\title{
An Analysis of an EFL Teachers' Guide: A Case Study
}

\author{
Ahmad Nazari \\ Department of Culture, Faculty of Education \& Society, University of Sunderland, Sunderland, SR1 3SD, UK \\ Correspondence should be addressed to Ahmad Nazari, ahmad.nazari@sunderland.ac.uk
}

Received 1 September 2010; Accepted 15 November 2010

Academic Editor: Yi-Shun Wang

Copyright ( $) 2011$ Ahmad Nazari. This is an open access article distributed under the Creative Commons Attribution License, which permits unrestricted use, distribution, and reproduction in any medium, provided the original work is properly cited.

\begin{abstract}
This paper is an attempt to analyse one of the documents which may affect the classroom activities of English as a Foreign Language (EFL) teachers, namely teachers' guides. It also explores the context at which the document is aimed and critiques how EFL teachers are advised to teach as well as how EFL is taught. As such, the paper stands where critical discourse analysis and language policy come together in the study of language policies in education. The teachers' guide chosen and the analysis carried out here are not necessarily concerned with their representativeness and typicality but with the opportunity they provide to the researchers and teachers to learn about such language policy documents and how language and language teaching objectives are represented in them. The issues raised in this paper will have relevance to the EFL teachers' guides and EFL education in other contexts, as these issues are likely to be true of other EFL milieux.
\end{abstract}

\section{Introduction}

In some countries, ELT teachers' guides (TGs) not only serve as a source of pedagogical advice and instructions for teachers but are de facto a statement of the national (e.g., in Niger) syllabus since they include statements about the course objectives, the course content, implementation, methodology, and sometimes even assessment procedures [1]. Given that they can play such a crucial role in defining classroom activities, it is worth examining TGs to see how they may also be promoting certain values and principles. However, "literature concerning evaluation of TGs is extremely thin on the ground.... Materials reviews give scant attention to TGs, or ignore them completely..." [2]. Clearly, this is an underresearched area, and this paper seeks to address this lacuna by examining one teachers' guide, EFL Teachers' Guide used in Iranian high schools, in order to explore how it reflects and promotes a particular view of language learning and teaching; in other words a particular view of the ELT curriculum.

All curricula are, by definition, a selection of knowledge and how it should be transmitted and scholars of language policy studies critically examine language policy documents, such as TGs, in order to analyse and to understand their implicit assumptions and implications [3]. As language policy documents and their rationales are often taken for granted [3], the insights gained through such critical analyses can shed light on the underpinning values and principles behind such documents. As with many statements of principles, it is important to look "at policies in order to decide what they offer and what they deny us" - what they include and exclude and what this tells us about language education [4]. The following is one interpretation of a $T G$ in a particular setting but may hopefully provide a stimulus for examining other TGs in different contexts.

\section{Method of Description and Analysis}

To succinctly describe the content of the TG used in Iranian high schools, "categorical aggregation" [5] was applied with a focus on the EL course objectives as covered in the $T G$. Since the document underdiscussion was extensive, categorical aggregation, which is a strategic way of piecing instances together until something can be said about the document as a whole, was employed to enable the researcher to make sense of the case by sequencing and categorising properties until some important features appeared [5]. The categorical aggregation carried out here not only assembles and sequences the course objectives present in the $T G$ in order to portray a succinct description of the TG, but is also part of the analysis of the document until some interpretations can be offered (see [5]). This description is 
also in order because without that it would be difficult for the reader to make sense of the interpretation which follows the description. The description will enable the reader to have a better perspective from which to judge the merits of the researcher's points in relation to the $T G$.

To analyse the TG, I applied the "absences/presences technique" [6] implemented in critical discourse analysis of texts, as this technique helps the analyst to highlight the elements, aspects, and skills of language learning which are present in and/or absent from the document. It should be mentioned that "textual analysis can often give excellent insights about what is "in" a text, but what is absent from a text is often just as significant from the perspective of sociocultural analysis" [6].

\section{Description of the TG}

High school education in Iran comprises three years for single-sex students aged 14-17. In each year, an EFL textbook (written by the EFL experts of the Iranian Ministry of Education and published by this Ministry) is taught across the country. These textbooks consist of eight lessons each, and each lesson comprises a section on new words, a reading text, reading comprehension questions, speaking drills, writing exercises, language functions exercises, pronunciation drills, and vocabulary exercises. As a compulsory course, English is taught with three to four hours of practice per week. The three EFL textbooks of Iranian high schools are supplemented with a TG providing the EFL teachers with the objectives of the course and guidelines on how to apply the textbooks. The TG is written by one of the EFL experts of the Ministry, Parviz Birjandi, and published by the Ministry [7]. To the best of my knowledge, no newer version of this TG has been published. This TG covers the EFL course objectives in different forms: what the students are to learn and to do, what the teachers are to teach and to do, what language skills are to be practised, and what language items are to be learnt. Furthermore, this TG seeks to guide the teachers' practice without being dogmatic. Having these points in mind, it is now appropriate to describe the TG.

In the first chapter of the Teachers' Guide (pages 1 and 2), the role of Contrastive Analysis (CA) in EFL is highlighted. According to the TG, by applying CA procedures, it is possible to avoid L1 negative transfer into EFL learning. This is followed by a history of language teaching methodology and some basic principles of language teaching methods, emphasising that no method has priority over others and that being eclectic is the most workable and appropriate approach in teaching EFL.

In the second, third, and fourth chapters of the Teachers' Guide, various distinctions and dichotomies are explored: applied versus pure linguistics, learning versus acquisition, FLL (Foreign Language Learning) versus SLL (Second Language Learning), use versus usage, and language teaching methods versus eclecticism. Explicating these concepts, it is mentioned that teachers of EL "should always try to provide a combination of activities which are both related to the student's knowledge of formal properties of the language (i.e., usage) and the ability to apply this knowledge in communicative contexts (i.e., use)" (Teachers' Guide, Page 21 ), and that teachers are justified in adhering to an eclectic approach in their teaching activities because there are no best methods. It is also reiterated that "through great emphasis on the communicative features of language and presenting a functional view of language in the classroom, the teacher will be able to encourage the students to practise the learned items over time and use them for communicative purposes...." (Teachers' Guide, Page 19). The rest of the Guide is allocated to answer keys to the exercises in the textbooks.

\section{The Four Skills}

In chapter five, the objectives of the EFL course are defined in terms of four skills: reading, listening, speaking, and writing. The importance of learning receptive skills before developing productive skills is stressed: "A word (or sound or construction) is often acquired by first being perceived and later by being produced" (Teachers' Guide, Page 50).

According to the $T G$, one of the tasks of the teacher is "to train students in a number of skills they will need for the understanding of reading and listening texts" (Teachers' Guide, Page 55). A section entitled "Reading" expounds the two types of reading to be carried out in the EFL classes: reading aloud to improve the students' pronunciation accuracy and silent reading to enhance their reading comprehension ability. The reading activity should be followed by tasks designed to check the students' reading comprehension. It is also recommended that teachers utilise reading texts as a basis for oral discussions in order to improve the students' speaking ability (Teachers' Guide, Page 58-61).

Once the reading objectives of the EFL course have been illustrated, a section entitled "Listening" is presented. It is made clear that the immediate objectives of listening activities for students are "to understand the teacher well enough to participate in the class activities, to understand their classmates in order to be able to interact with them in communicative contexts, and to practice with tapes" (Teachers' Guide, Page 62).

In the next section of the TG, the nature of communication and productive skills is explained in detail and certain distinctions are drawn between speaking and writing. The speaking objectives of the EFL course are then pointed out: enabling students "to use the material they are learning to speak to someone else", "to participate in the class activities using the target language", and "to convert their thoughts to an oral message within the range of the material they have used in the class" (Teachers' Guide, Page 71). Suggestions are also made regarding certain techniques which may be employed to achieve the above objectives, such as starting with prespeaking activities and moving to communicative types of exercises.

In the next section, given over to writing, it is reiterated that writing is "the most demanding of the foreign language skills... (and) ...should continue, at every level, to be developed further" (Teachers' Guide, Page 74). It is stated that the ultimate objective of teaching writing is to enable students to communicate their thoughts and to convey messages in the written mode. At the same time, the 
consolidation of linguistic forms and of the mechanics of writing has not been neglected as an objective at lower levels (Teachers' Guide, Page 76-77).

\section{Three Further Objectives}

According to the Guide, the other objectives of the EFL course are to teach and learn pronunciation, grammar, and vocabulary. These objectives will be restated here.

As far as teaching and learning pronunciation is concerned, the Guide states, "our goal in teaching pronunciation is based on pragmatic concerns; we want our students to understand and to be understood" (Teachers' Guide, Page 80).

The Guide also elaborates on the pronunciation of vowels, consonants, and diphthongs as well as the phonemic symbols for the transcription of each. Furthermore, it points out that one useful way to teach phonemes and to train pupils in aural discrimination is the use of minimal pairs such as "thin" and "tin", and that the sound system can be learnt through imitating the teacher or a tape (Teachers' Guide, Page 88).

In a section entitled "Grammar", the Guide asserts that any grammar teaching should be integrated within functional and communicative approaches. It should also be presented cyclically, which entails periodically reintroducing it into new contexts (Teachers' Guide, Page 101). Finally, it concludes "while a grammatical syllabus is in our view indispensable, it should no longer be regarded as the sole organising principle of curriculum design. To be precise, the grammar syllabus does not stand alone; it must be related to other subsystems of language" (Teachers' Guide, Page 101).

The Guide also points out that "teachers should try to put whatever grammatical features are being taught into a meaningful context of practical use so that meaning is completely clear" (Teachers' Guide, Page 104). In addition, it emphasises that learners should be practised in not only contextualising but also decontextualising grammar rules. Enabling students both to synthesise and to analyse the formal features of English in order to achieve structural accuracy is thus another objective of the EFL classes. To attain this objective, the Guide suggests using a sequence of mechanical, meaningful, and communicative drills through either an inductive or a deductive approach (Teachers' Guide, Page 106-107).

According to the Guide, the development of a rich vocabulary should be included among the objectives of the EL classes. It maintains that words should be taught and learnt in context, and that a further objective is to help learners to develop skills in inferring and guessing the meaning of unknown words from the context. To achieve this objective and also to assess the extent of this achievement, the Guide suggests the use of cloze exercises, word-in-context exercises, context enrichment exercises, and the application of realia (Teachers' Guide, Page 114-115).

The Guide also emphasises that gaining a thorough grasp of all new lexis is only one objective of vocabulary learning; the other objective is to enable students to produce the new lexis through adequate practice. The techniques suggested by the Guide include applying word games and puzzles, asking students to present synonyms, antonyms and associated words as well as the use of cloze exercises. Composition writing and conversation are also considered as ways of activating students' vocabulary (Teachers' Guide, Page 1118122).

\section{Assessment}

Although no specific section in the $T G$ is devoted to the assessment of the course, here and there guidelines and advice are provided to the teachers on the assessment of the students. For instance, on page 121, the TG states, "Multiple-choice questions and cloze tests can provide us with valuable means of evaluating our students' abilities in word recognition or productive use of new words." On page 127, the teachers are advised to ask their students questions based on reading passages and to tell them to summarise the passages orally. A further example appears on pages 157 and 170 where the teachers are advised to ask the students to perform dialogues and create new ones. These guidelines seem to provide the teachers with pointers regarding how they should assess their students' EFL skills.

\section{Analysis and Interpretation of the TG}

The Iranian high school TG states that the objective of the EFL course is to help the students acquire communicative competence as well as linguistic competence: "...the acquisition of communicative competence is as necessary for foreign language learners as the acquisition of linguistic competence" (Teachers' Guide, Page 70). To this end, language is literally disintegrated into four skills, and the skills are further itemised into certain subskills. The content of the TG presents communicative competence as an objective that could be achieved without situating language activities in the sociocultural content of language. In fact, the above description reveals that the acquisition of social and cultural aspects of language, that is, sociocultural competence, the ability to effectively and aptly operate within a different sociocultural context, is absent from the objectives stated in the TG.

Handford [8], proposing an approach for enabling students to effectively navigate through socioculturally embedded situations, depicts sociocultural competence in the following way:

If we were to meet an adult native speaker who had grown up in a place where there were no other people, but sufficient language input, through, for example, tapes, for that person to be in linguistic terms a fluent speaker, then it seems reasonable to say that this person would in all likelihood be regarded as socially dysfunctional. Our unfortunate would not know how to deal with the most simple situations, and unless he or she were protected and educated, a sorry end may well be just around the corner. 
The construct of communicative competence

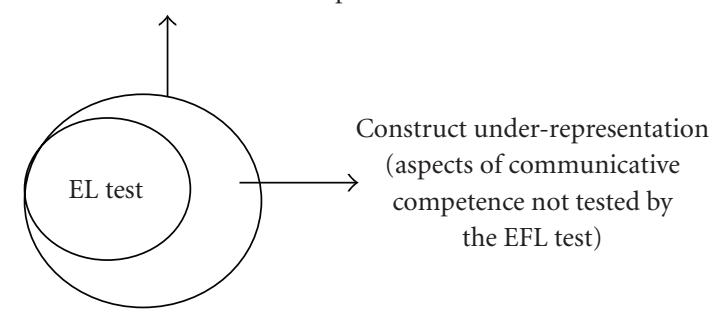

FIGURE 1: One of the factors affecting test construct validity.

... potential for confusion is therefore plentiful and plain. In a liberal Western country such as England, men coming from a more patriarchal society could easily find themselves being rebuked or criticised, and might feel at a loss as to why. When and to whom the words "Thank you" are required to be said in England is a notoriously confusing area. (Handford 2002: page 1)

There seem to be at least two reasons for the absence of the sociocultural aspects of language from the TG. The first of these is the effects of the annual Iranian nation-wide university entrance examination in Iran. The second reason is the effects of a grammar-based teaching methodology. These issues will be discussed in the following sections.

\section{Language Test Washback}

Those high school graduates who intend to pursue a university education are required to sit a national university entrance examination held annually. Almost 1,500,000 applicants take this norm-referenced high-stakes examination, which is usually in a multiple-choice format. Based on the result of this examination, nearly 300,000 applicants matriculate each year. Part of the examination consists of an English language test containing 25 questions: 5 grammar, 10 vocabulary, 5 cloze (mostly testing vocabulary knowledge), and 5 reading comprehension questions. The grammar and vocabulary items are sententially contextualised and are discrete-point tests. The cloze and reading comprehension are each tested through one short passage and are integrative tests. The content and layout of this test ignores the sociocultural practices of the English language (see http://www.nosratco.com/honarom86.pdf questions 76-100 on pages 13-15 for an example of a real test). In testing terms, what can be seen in the EL component of the university entrance examination is underrepresentation of the construct of communicative competence. Construct underrepresentation occurs when a test reflects an incomplete picture of communicative competence [9]. In other words, underrepresentation oversimplifies the construct by requiring too little from the testee. Figure 1 can further clarify the point.

It should be reiterated that the construct of communicative competence needs to embrace knowledge of the sociocultural dimension of language [10]. Since the EFL test under discussion does not assess the testee's command of sociocultural aspects of the language, the construct of communicative competence is under-represented by the test. In other words, the test is an autonomous language test in that the sociocultural practices of language are not assessed by the test items [11].

The failure to assess the sociocultural dimension of language in the English language test in a nation-wide highstakes examination may have affected the composition of the $T G$ and the course objectives. In other words, the $T G$ does not call for the improvement of high school learners' sociocultural savoir-faire because the sociocultural aspects of language are not assessed in the most important educational examination of the country. Ostovar Namaghi, interviewing experienced high school Iranian English language teachers, expresses it thus "the curriculum is not designed by language teachers, but is mandated from above or determined by the need to deal with standardised tests" [12]. He continues, "The testing scheme is fixed. The accuracy of the scheme is taken for granted. Teachers cannot replace the scheme. This external given has overshadowed teachers' work. Teachers do not teach the book, they teach to the test" [12]. One of his interviewees succinctly states how the language tests have affected the high school language programme: "The centralised control of curriculum and assessment shapes my pedagogic practice. This superimposed scheme has homogenised language education at high school level throughout the country" [12]. This is referred to as washback in the literature on language testing. The teachers' practices can be attributed to various causes including the $T G$ and test washback. However, as no claims about the effects of washback can be sustained without verification, the relationship between the university entrance examination, the $T G$ and teachers' practices should be researched by applying observations, questionnaires, and even further interviews. This could be considered as one of the avenues for further research recommended by this paper.

\section{Widespread Language Teaching Method}

In addition to the likely effects of the nation-wide university entrance examination on the composition of the $T G$ and the objectives of EFL at high school level, the effects of a grammar-based teaching methodology are also worth exploring. In this regard, one of the teachers interviewed by Ostovar Namaghi says, "Lecturing is the dominant mode of teaching. Discussion may develop learners' ability but doing so entails not only lagging behind the schedule but also lead to generating knowledge not specified in the syllabus" [12]. Similarly, Nazari [13], observing high school EL classes and interviewing EL teachers in Iran, concludes that teaching grammar, vocabulary, and reading comprehension is the prime educational commitment of the EFL teachers. One of his participants says:

Having taught the new vocabulary, I want students to use those new lexical items in sentences orally. Then I teach the reading text and I want one of the good students to give a summary 
out of the text. I also ask other students to present summariesvoluntarily. Afterwards, I teach the structure mentioned in the book by using certain traditional techniques. Besides, when I teach reading, I ask students to read the text silently paragraph by paragraph and then answer my questions which are based on the already read paragraph. (Nazari 2002: page 145)

Another interviewee teacher states, "My students seem better at receptive skills than productive skills. Students learn grammar, reading and, to some extent, vocabulary" [13]. This ubiquitous scenario may, one way or another, have affected the high school EL programme, with the inevitable consequence that Iranian high school students' linguistic competence is developed at the expense of their sociocultural competence.

\section{Double Recontextualisation of English}

As was mentioned earlier, Nazari [13] concludes that Iranian high school EFL focuses on the improvement of the mechanical aspects of language. I would like to suggest some explanations for this. One interpretation could be that there appears to be a "recontextualisation" of the English language [14], that is, "the delocation, relocation and refocusing" of the real-world English discourse which have caused the abstraction of that discourse from its sociocultural aspects and its communicative nature. What goes on in the classrooms can be called "classroom English" (i.e., English restricted to vocabulary, structures, and certain reading comprehension materials), whereas according to Hill and Parry, what nonnative speakers need to learn is the "real-world English" [11] or ideological language in Dubin's sense [15]. This is in line with what I have already argued: I suggested that not only do the course objectives draw upon an atomised, study-skills, and autonomous model of communicative competence [15], but also the classroom activities and processes seem to be a recontextualisation of the real-world English. In other words, there is a double recontextualisation of the English language: the recontextualisation of the concept of communicative competence which has occurred in the formulation of the course objectives and a further recontextualisation of the English language which has taken place in the classroom. The following diagram helps to further demonstrate the concept of double recontextualisation occurring in the EFL programme.

I have already elaborated on the way in which the initial change (see stage (B) in Figure 2) has occurred: through the absence of the sociocultural dimension of the English language from the formulation of the course objectives and the employment of an atomised study-skills approach in defining them. I have also explained that the second reduction (see stage (C) in Figure 2) seems to be due to two factors: test washback and a widespread teaching methodology. It should be mentioned that the latter reduction may also be due to practical constraints such as class sizes, contact hours, and the volume of the instructional materials (see Ostovar Namaghi [12] for a discussion of the practical constraints).

\section{Significance of Sociocultural Competence}

Whatever the reason is for the absence of a sociocultural dimension from the $T G$, and thus from the course objectives, it is out of line with the suggestions of language educationists and cultural linguists regarding the importance of improving sociocultural competence in language education (see, e.g., [16]). Learning a language without the acquisition of the sociocultural aspects of that language, I suggest, is a restricted and "reductionist" model of literacy which hardly leads to a discourse-sensitive communicative competence [17]: a communicative competence which is responsive to the sociocultural discourses of L2. Language teaching and learning is more than skills training, as mere skills training is likely to lose sight of sociocultural practices. As Williams [18], underscoring the role of sociocultural learning in language education, points out, "The learning of a foreign language involves far more than simply learning skills, or a system of rules, or a grammar; it involves...the adoption of new social and cultural behaviours and ways of being..." By the same token, Roberts et al. [16] assert, "Although the foreign language learner may not be joining a new community in any permanent way, their goal is to understand the social practices of that community and to behave in ways which will allow some continuing relationship with it". The implications of marginalising the dimension of sociocultural competence in language education are clear: a language can hardly be learnt or taught properly without attending to the sociocultural aspects of the community in which it is used, since lack of L2 sociocultural knowledge leads to inappropriate language behaviours, socio-pragmatic failures, and breakdowns in communication $[8,19]$.

In Dubin's [15] words, communicative competence has at least two meanings. The first of these, the autonomous meaning of communicative competence, entails an idealised speaker-hearer's socioculturally neutral ability to communicate. Dubin contends this meaning of communicative competence leans towards Chomsky's linguistic competence, which is narrow and reductionist. By contrast, according to Dubin, the ideological meaning of communicative competence signifies what Hymes elaborated on in an attempt to separate it from Chomsky's linguistic competence. This latter meaning is a broad definition incorporating the sociocultural aspects of language ([15] cited in [20]). In fact,

Hymes maintained that the competence, Chomsky had talked about, was "linguistic" competence, a limited aspect of a broader concept he called "communicative" competence, which included not only linguistic competence but also other aspects, specifically sociocultural dimensions [10]. According to Hymes, a theory of language needs to deal with "the constitutive roles of sociocultural features ..." [10]. (Nazari 2007: 202)

As the language activities recommended in the $T G$ are not situated in sociocultural practices, a "study-skills", "autonomous" approach to the illustration of the course objectives and communicative competence has been given 


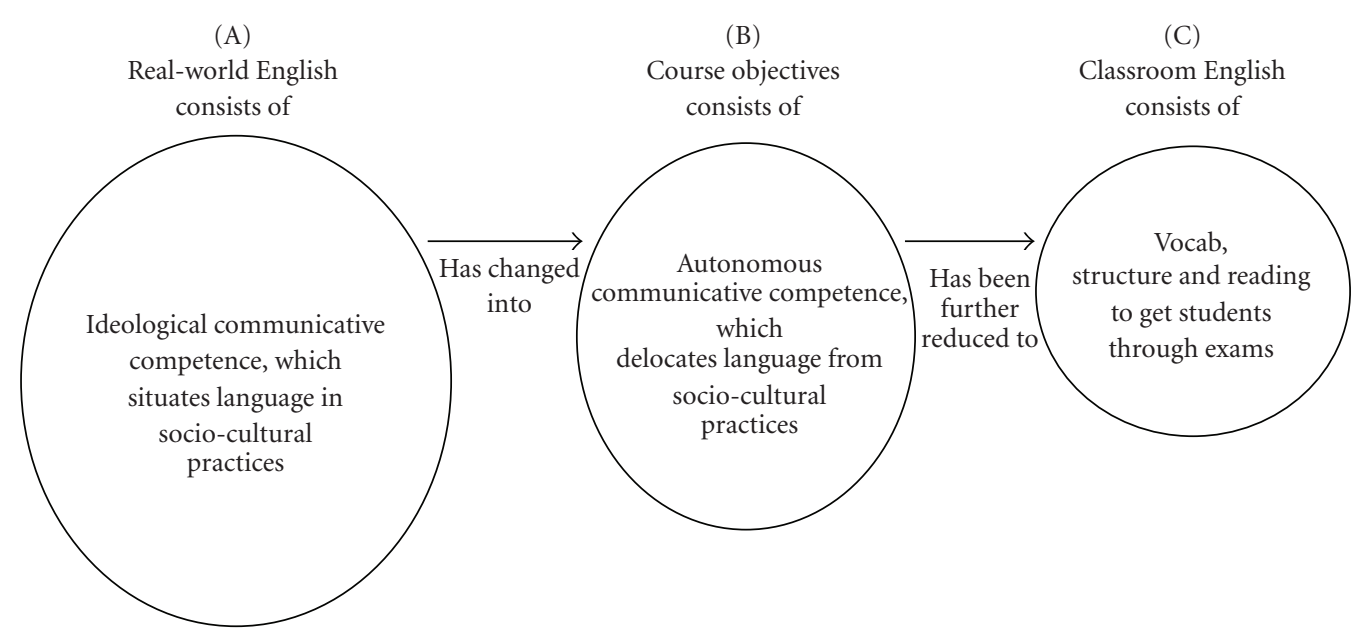

FIgURE 2: Double recontextualisation of the English language.

preference over an "ideological" model (i.e., a broader perspective on language, communication, and communicative competence). This ideological model is what Ethnography of Communication tradition elaborated and expounded as communicative competence [15], a model in which the significance of sociocultural practices and the embeddedness of language in these practices are underlined.

If language learning and teaching activities are to be embedded in sociocultural practices, the question remains as to which language community's sociocultural practices should be the focus of the learners. This, I suggest, depends on negotiations between the teacher and learners. Similarly, the selection of the sociocultural topics to be explored would be the outcome of the teacher-learner negotiations [21]. Although I am aware that English in Iran has started moving towards EIL (English as an International Language) [22] and I by no means intend to advocate native-speaker norms, I contend we should take heed of what Timmis [23] points out regarding learning and teaching English. Timmis, drawing on a survey collected from 600 participants in 45 countries, argues that students, no matter whether they use or anticipate using English primarily with English-speaking nationals, would like to conform to native speaker norms [23]. In sum, I believe that if there were a requirement that the language teaching and learning activities suggested in the $T G$ should be embedded in sociocultural practices, the decision about which community's sociocultural practices to investigate could be left to the students and teachers.

\section{Summary and Conclusion}

This paper centred on a description, analysis, and interpretation of the EFL TG used in Iranian high schools, with a focus on the EFL course objectives as formulated in the $T G$. Through this analysis, I argued that the sociocultural aspects of the language have been marginalised, and the focus is reduced to the enhancement of linguistic competence. In effect, the marginalisation of the acquisition of sociocultural competence has resulted in applying a reductionist, studyskills, and atomised model of language in the statement of the course objectives, in that language is literally disintegrated into skills and subskills.

In essence, the subject of the present study can be considered a "telling case", as the insights gained into the nature of the EFL TG of Iranian high schools may be potentially illuminating in the analysis of other nationally produced EFL TGs. For instance, to analyse such language policy documents, analysts can apply the categorical aggregation technique to reproduce an analysable version of the document and then use the absences/presences technique to find out what the document proffers and what it omits. To interpret and discuss the issues raised through the analysis, the analyst should also draw on the context at which the document is aimed, as the document can affect the context and be affected by it (see, e.g., the above sections on language tests, language teaching methods, and the recontextualistion of the English language). In addition to depicting one of the approaches used in analysing certain language policy documents, the analysis carried out and the issues raised here are also likely to be informative in the improvement of such TGs. Needless to say, effective TGs can make contributions to enhancing our teaching activities [24].

Methodologically, the issues raised in this paper are a contribution to the development of the theory. In other words, the issues I have raised here are within the framework of analytical induction. These issues are essentially meant to be taken by other researchers and explored in their own contexts. Analytical induction is a qualitative technique whereby the researcher seeks to offer provisional explanations of a case by examining it. If the inspection of other cases shows that the case researcher's initial explanation is not rigorous, the explanation will be revised and reformulated. The research will go on either by the case researcher themselves or other researchers until the explanation cannot be contested any longer [25]. This study is meant to contribute to the development of such an explanation. 


\section{References}

[1] I. Halilou, A formative evaluation of the implementation of a new syllabus and course book for secondary schools in Niger, Ph.D. thesis, University of Warwick, Coventry, UK, 1993.

[2] M. Hemsley, "The evaluation of teachers' guides-design and application," English Language Teacher Education and Development, vol. 3, no. 1, pp. 72-83, 1997.

[3] J. W. Tollefson, "Introduction: critical issues in educational language policy," in Language Policies in Education: Critical Issues, J. W. Tollefson, Ed., pp. 3-17, Lawrence Erlbaum Associates, Hillsdale, NJ, USA, 2002.

[4] J. Edmondson, Understanding and Applying Critical Policy Study, International Reading Association, Erie, Pa, USA, 2004.

[5] R. E. Stake, The Art of Case Study Research, SAGE Publications, Oaks, Calif, USA, 1995.

[6] N. Fairclough, Critical Discourse Analysis, Longman, New York, NY, USA, 1995.

[7] P. Birjandi, EFL Teachers' Guide, Iranian Ministry of Education, Tehran, Iran, 1994.

[8] M. Handford, "Developing sociocultural competence in the ESL classroom,” 2002, http://www.nottingham.ac.uk/english/ nlc/handford.pdf.

[9] M. Tim, Language Testing, Oxford University Press, Oxford, UK, 2000.

[10] D. H. Hymes, "On communicative competence," in Sociolinguistics, J. B. Pride and J. Holmes, Eds., Penguin Books, London, UK, 1973.

[11] C. Hill and K. Parry, Eds., From Testing to Assessment, Longman, London, UK, 1994.

[12] S. A. Ostovar Namaghi, "Forces steering Iranian language teachers' work: a grounded theory," The Reading Matrix, vol. 6, no. 2, pp. 90-105, 2006.

[13] A. Nazari, The EFL curriculum in an Iranian high school: a qualitative evaluation research approach, Ph.D. thesis, King's Collage London, London, UK, 2002.

[14] B. Bernstein, Pedagogy, Symbolic Control and Identity: Theory, Research, Critique, Rowman \& Littlefield Publishers, Oxford, UK, 2000.

[15] F. Dubin, "Situating literacy within traditions of communicative competence," Applied Linguistics, vol. 10, no. 2, pp. 171$181,1989$.

[16] C. Roberts, M. Byram, and A. Barro, Language Learners as Ethnographers, Multilingual Matters, Clevedon, UK, 2001.

[17] B. V. Street, "Academic literacies: a critical perspective," King's English, vol. 3, no. 1, pp. 32-36, 2000.

[18] M. Williams, "Motivation in foreign and second language learning: an interactive perspective," Educational and Child Psychology, vol. 11, no. 2, pp. 77-84, 1994.

[19] E. Hinkel, Ed., Culture in Second Language Teaching and Learning, Cambridge University Press, Cambridge, UK, 1999.

[20] A. Nazari, "EFL teachers' perception of the concept of communicative competence," ELT Journal, vol. 61, no. 3, pp. 202-210, 2007.

[21] L. Sercu, "Autonomous learning and the acquisition of intercultural communicative competence: some implications for course development," Language, Culture and Curriculum, vol. 15, no. 1, pp. 61-74, 2002.

[22] M. R. Talebinezhad and M. Aliakbari, "Evaluation and justification of a paradigm shift in the current ELT models in Iran," Linguistik Online, vol. 10, no. 1, pp. 1-8, 2002.
[23] I. Timmis, "Native-speaker norms and international English: a classroom view," ELT Journal, vol. 56, no. 3, pp. 240-249, 2002.

[24] A. Cunningsworth and P. Kuse, "Evaluating teachers' guides," ELT Journal, vol. 45, no. 2, pp. 128-139, 1991.

[25] G. W. Ryan and H. R. Bernard, "Data management and analysis methods," in Qualitative Research, N. K. Denzin and Y. S. Lincoln, Eds., pp. 769-803, Sage Publications, London, UK, 2000. 


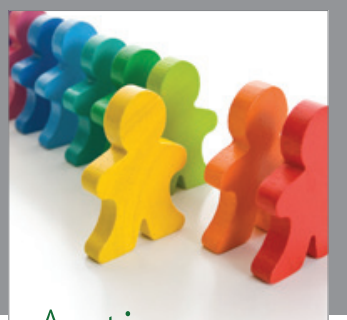

Autism

Research and Treatment
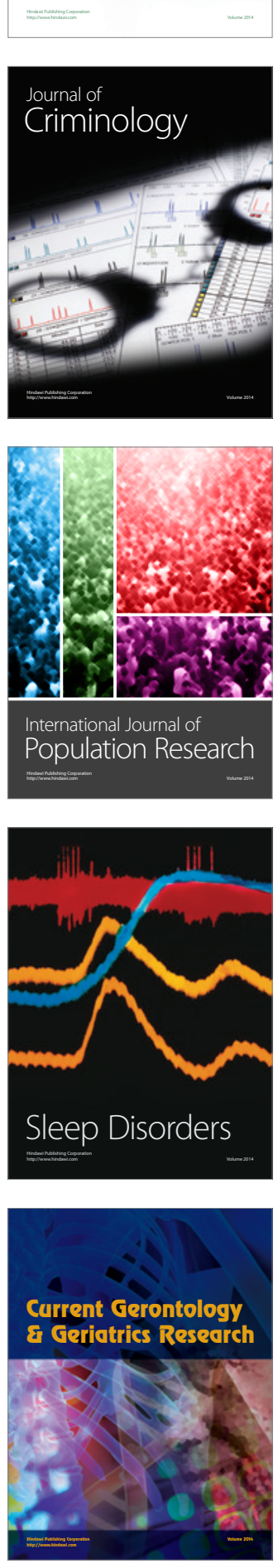
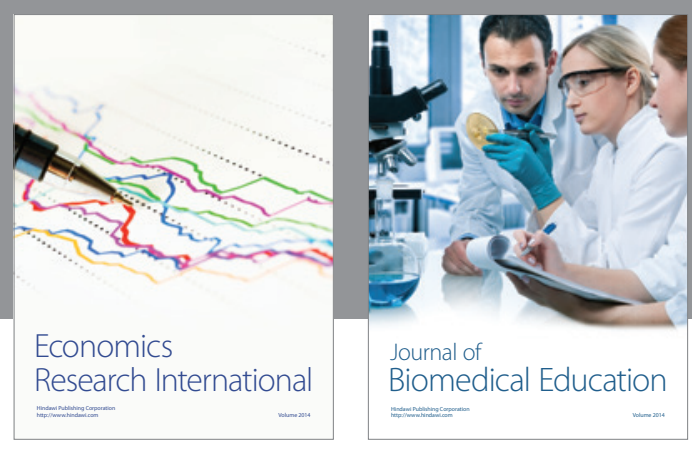

Journal of

Biomedical Education

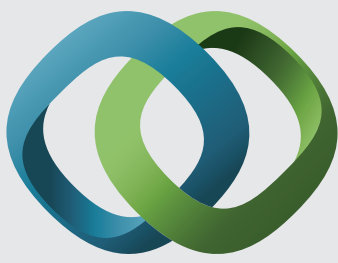

\section{Hindawi}

Submit your manuscripts at

http://www.hindawi.com
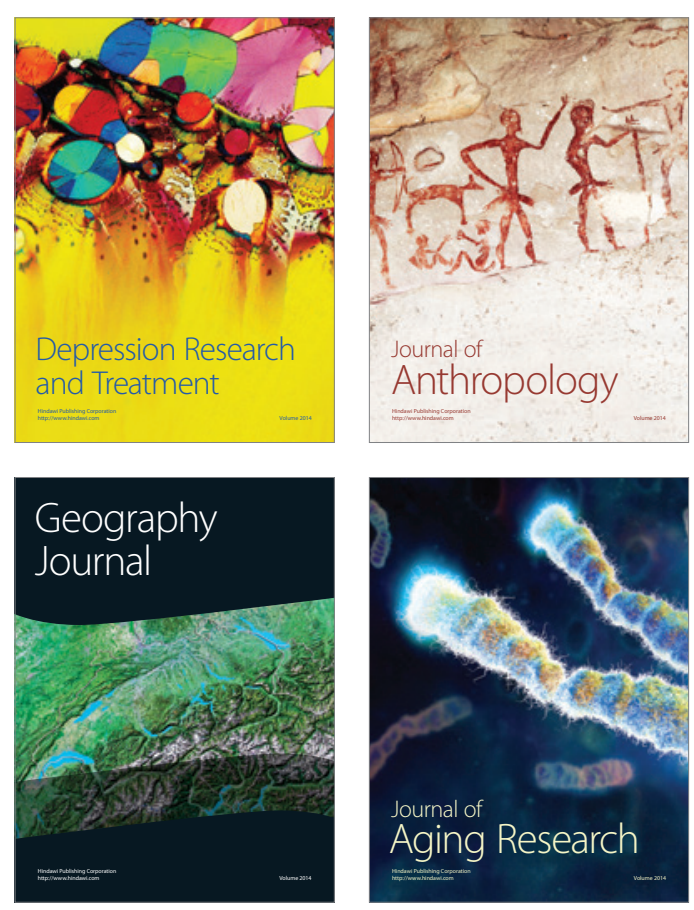

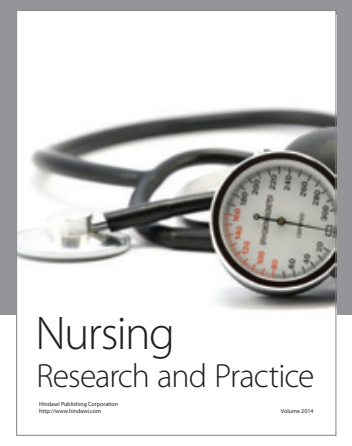

Nursing

Research and Practice

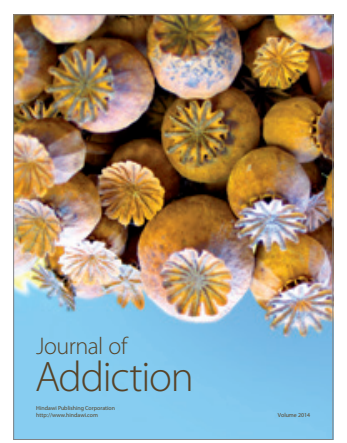

Child Development

Research

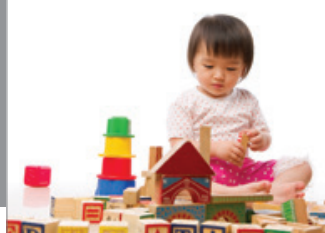

迥
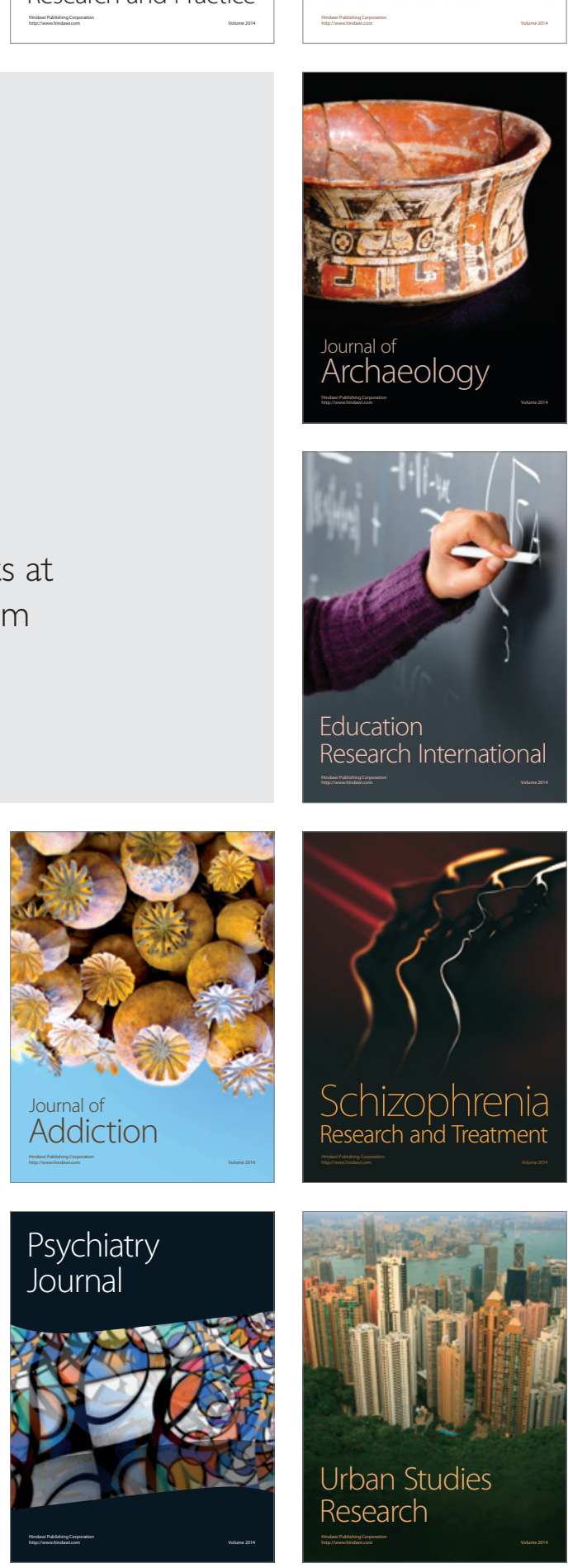